\title{
Practices and Behaviors During the COVID-19 Pandemic in Patients With Rheumatoid Arthritis Who Attended Previously to An Educational Program. A Cross-Sectional Study
}

Pedro Santos-Moreno ( $\sim$ pedrosantosmoreno@hotmail.com )

Biomab IPS

Diana Buitrago-Garcia

University of Bern

Fernando Rodriguez-Florido

Biomab IPS

Guillermo Sánchez-Vanegas

Fundación Universitaria de Ciencias de la Salud

\section{Research Article}

Keywords: Patient Care Team, Rheumatoid Arthritis, COVID-19, Pandemic

Posted Date: January 19th, 2021

DOl: https://doi.org/10.21203/rs.3.rs-135024/v1

License: (c) (1) This work is licensed under a Creative Commons Attribution 4.0 International License.

Read Full License 


\section{Abstract}

Background: To describe the practices and behaviors of patients with rheumatoid arthritis (RA) who attend to a face-to-face education program, during the quarantine of the COVID-19 pandemic.

Methods: Patients who attended previously a face-to-face education program, responded to a telephonic survey in July 2020. The survey included questions about their practices related to the COVID-19 pandemic, SARS-Cov-2 symptoms, adherence to rheumatoid arthritis treatment, virtual rheumatology consultancy compliance and, the influence of news on their adherence.

Results: A total of 260 patients participated in a survey. In July $202088 \%$ of patients had accessed a telemedicine-based and $12 \%$ a face-to-face rheumatology consultation. $3.5 \%$ of patients reported having been less adherent to pharmacological therapy due to information received through media or social networks. In general patients had been compliant with COVID-19 prevention recommendations. Only one patient was positive for SARS-CoV-2 and reported only flu symptoms without any complications. Patients highlighted the necessity to have information and education about the relationship between rheumatoid arthritis, its treatment, and COVID-19.

Conclusions: An educational program is a helpful tool to maintain high adherence rates to the RA treatment despite of the new challenges associated to the pandemic; Patient-centered education programs should continue to address the patient's concerns and beliefs about their disease and COVID19.

\section{Introduction}

The new coronavirus disease has become a public health emergency that has not been seen for generations. The COVID-19 disease leads to an extreme immune activation and cytokine response and constitutes a big risk and a challenge for patients with inflammatory conditions such as rheumatic diseases (1). Rheumatoid arthritis (RA) is a condition that starts during adulthood between 40 and 50 years of age, usually the disease is accompanied with other comorbidities mainly cardiovascular (2). In addition, pharmacological treatment could lead to immunosuppression thus a bigger risk of infection $(3,4)$. Due to above, patients with RA have been considered as high-risk population during the COVID-19 pandemic. One of the recent innovative strategies for achieving remission or low disease and, improve other aspects of the patients with RA is to implement multidisciplinary care, with an educational component. This strategy has demonstrated a relationship with positive clinical outcomes and, an improvement in the overall patient's satisfaction (5). Education programs for patients with RA can improve functional disability having better results than information only or conventional counseling (6).

During the COVID-19 rheumatologists and health-care professionals have faced many challenges in order to provide an adequate follow-up and treatment to RA patients. One of them, has been the establishment of lockdown especially for populations older than 60 years and the limitation of having face-to-face consultations (7). As a result, many telemedicine has become an alternative to treat patients with 
rheumatic conditions. Patients have been able to get access to medical services and medications without hospital appointments via online tools (8). In Colombia, the Ministry of Health ordered an outpatient care procedure for the population in isolation; by tele-counselling, patients were offered consultation by telemedicine due to the high epidemiological risk of COVID-19; in the case of educational programs, it was mandatory to pause them or implement virtual education alternatives (9).

Our aim was to describe the practices and behaviors during the quarantine of the COVID-19 pandemic of patients with RA who attended previously a face-to-face education program.

\section{Methods}

We conducted a cross-sectional study. We included participants who attended to an educational program for patients with RA at a specialized center. Our educational program called UNIVERSITAR started in August 2019 (10). This face-to-face program was designed to last two years, promote patients among three levels of education, and finally, have patients with enough education about their condition, that can educate, guide and, support their peers and others who have the same health condition(11). Because patients with RA are considered as a high-risk population for Covid-19 infection and complications, the educational program had to be stopped in March 2020 due to the pandemic.

We included patients who have signed-up in our educational program and responded to a telephonic survey. This survey aimed to know about their practices, beliefs, behaviors and symptoms (within 2 weeks prior to the survey) on COVID-19 during the lockdown. In addition, we asked them about adherence to pharmacological treatment and, the new implemented model of telemedicine. An ethics committee, approved this study and all included patients agreed to participate in the survey.

\section{Study Variables}

We collected sociodemographic information; patients were asked about their compliance to the RA disease treatment during the pandemic, development of any symptoms related to COVID-19, the relationship with people to be at risk of having COVID-19 and the compliance to the new measures recommended by the Colombian government. Data was collected during June of 2020.

\section{Statistical Analysis}

We performed a descriptive analysis; continuous variables are presented as median and interquartile ranges and categorical variables as relative frequencies. All analyses were carried out using Stata $15{ }^{\circledR}$.

\section{Results}

We obtained information on 260 patients; mean age of the respondents was 60 years IQR (54-66), 93\% were female. The median time since the RA diagnosis was 15 years IQR (8-24), $86 \%$ of patients were 
receiving more than one conventional DMARDs (see Table 1).

Table 1

Characteristics of RA patients who underwent to educational program previously to COVID-19 pandemic

\begin{tabular}{|ll|}
\hline $\mathbf{n}=\mathbf{2 6 0}$ & \\
\hline Demographics & 60 (54-66) \\
\hline Age, years (median IQR) & 93 \\
\hline Female (\%) & 7 \\
\hline Male (\%) & \\
\hline Civil Status & 26 \\
\hline Single (\%) & 45 \\
\hline Married (\%) & 20 \\
\hline Divorced (\%) & 10 \\
\hline Widowed (\%) & \\
\hline Education & 24 \\
\hline Elementary School (\%) & 39 \\
\hline High School (\%) & 37 \\
\hline College education (\%) & \\
\hline Therapy & 86 \\
\hline Conventional DMARDs (\%) & 14 \\
\hline Biologic DMARDs (\%) & \\
\hline
\end{tabular}

Management of rheumatoid arthritis during the COVID-19 lockdown

During the previous face-to-face educational program, main goals were to promote knowledge about disease, consultations and, adherence to treatment and to the multidisciplinary care model. After the beginning of lockdown, the RA center implemented a new model of telemedicine that started with rheumatology. When patients where asked if since the lockdown they have accessed a telemedicine based consultation with a rheumatologist $88 \%$ of answers were positive, while $75 \%$ of participants reported to have attended to other specialties (35\% have attended to the physiatrist, $29 \%$ the psychologist, $8 \%$ physical therapy and, $3 \%$ to nutrition). In general, patients understood the necessity of being treated despite the new model of consultation. We did not find any differences between gender, educational level and civil status and the adherence to virtual consultations. 


\section{Behaviors acquired during COVID-19 pandemic}

We asked to participants if they had stopped taking their pharmacological treatment because they received negative information regarding immunosuppressive effect of medications that showed negative effects when patients have COVID-19 infection; nine patients (3.5\%) reported to have been less adherent due to the above reason. Among 260 patients, 11 reported to have been taking antimalarials as treatment for RA and only 1 patient stated to have stopped taking it due to the news about supposed cardiotoxicity for patients who were treated for COVID-19. Additionally, we asked about the prevention measurements taken during the pandemic; $98 \%$ reported to have stayed in their houses during since the lockdown was stablished in Colombia on March 2020, and have implemented or increased hand washing from one or none to more than three times per day. $8 \%$ of respondents lived with people who were at bigger risk of having SARS-CoV-2 (i.e. health care professionals, workers at public transportation, and supermarkets among others), the main measurement taken was to be completely separate from the person at risk to avoid contagion and maintaining hygiene measures and physical distancing (Fig. 1).

\section{Symptoms of COVID-19}

In total $24 \%$ of participants reported to experience new symptoms potentially associated to COVID-19 within two weeks prior to the survey. The most frequent reported symptom was headache $22 \%$, followed by muscle pain or fatigue $11 \%$ (see Table 2); three patients reported to have been in contact with someone who was suspicious or diagnosed with COVID-19 and tested negative. One patient who had been exposed to the virus thought a family member tested positive for SARS-CoV-2. The patient reported to have mild symptoms and recovered after two weeks. Seven patients reported to have contacted the emergency services due their symptoms and the medical personal ruled out the necessity of testing for SARS-CoV-2 due to the criteria for diagnosis in Colombia (Not been exposed to a positive SARS-CoV-2 and having minor symptoms). 
Table 2

Reported symptoms related to SARS-CoV-2 RA patients who underwent to educational program previously to COVID-19 pandemic

\begin{tabular}{|lll|}
\hline Symptoms $^{1}$ & Participants reporting & Participants not reporting \\
\cline { 2 - 3 } & $\mathbf{n}(\%)$ & $\mathbf{n}(\%)$ \\
\hline Headache & $58(22)$ & $202(78)$ \\
\hline Muscle pain or fatigue & $29(11)$ & $231(89)$ \\
\hline Nasal congestion & $19(7)$ & $241(93)$ \\
\hline Cough & $11(4)$ & $249(96)$ \\
\hline Sore Throat & $11(4)$ & $249(96)$ \\
\hline Diarrhea, vomiting or nausea & $7(3)$ & $253(97)$ \\
\hline Loss of smell or taste & $5(2)$ & $255(98)$ \\
\hline Fever & $2(1)$ & $258(99)$ \\
\hline 1. Reported within 2 weeks & & \\
\hline
\end{tabular}

Finally, when we asked about continuing the educational program via online platforms; patients referred their interest in continuing the educational program. We found barriers such as lack of access to internet, lack of informatic knowledge/skills or, lack of time. However, many of them requested to have talks about rheumatoid arthritis and COVID-19.

\section{Discussion}

Patients with rheumatoid arthritis are at high risk for COVID-19. Due to the implementation of lockdown and quarantine measures, patients had to be at home all the time limiting them from accessing to their educational program and face-to-face care. In our study we found that beyond the circumstances patients have continued to be adherent to their treatment and consultations; we found a small proportion of patients (3.5\%) with lower adherence to treatment. (12). In contrast, other authors have found loss of treatment adherence in rheumatic patients due to the pandemic; Fragoulis et al found a possible modification of treatment in $24.8 \%$ of patients(12); Michaud et al reported that $42 \%$ of patients had a change in treatment(13); Pineda-Sic et al found that $15 \%$ of patients also changed or discontinued treatment (14).

As some studies have shown COVID-19 has changed the perceptions of patients with RA about their medications and the uncertainties about the safety of them(12-14). Additional to these concerns, there is an enormous amount of false information provided by the internet or social network during these days (15). One of the limitations of our study is recall bias, since patients could have not remember all the information asked in the survey. Additionally, in this survey we did not ask about family meetings, and other preventive measures during the pandemic. 
online information for COVID-19 has been found difficult to read and understand thus, it is relevant to continue educational programs for patients in order to provide support and address patient's beliefs and concerns(16). Because of the estimated long-term duration of the pandemic, we believe that patient education programs must be re-invented and improved to adapt to new education forms through online alternatives, these non-formal education programs need to follow these examples and adapt to particular populations such as patients with RA.

\section{Declarations}

\section{Ethics approval and consent to participate}

This study is approved by the Human Research Ethics Committee (Comité de Ética en Investigación con Seres Humanos - CEISH del Hospital de San José) with approval number (CEISH) 0203-2018 and informed consent was obtained from the patients for participation in the study.

All methods were carried out in accordance with the institutional ethic guidelines and regulations.

All methods were conducted in accordance with the ethical standards of the Declaration of Helsinki. All methods were carried out in accordance with relevant guidelines and regulations.

\section{Consent for publication}

Consent was obtained from the participants for the publication of the data and results of the study.

\section{Availability of data and materials}

The authors declare that the database and other study materials are available for review at any time. All files, databases and other documents related to the study are available on a computer in our research office and with access only to the team of researchers.

\section{Competing interests}

PSM has received fees for conferences, counseling, advisory boards; also travel to academic meetings expenses and research grants from: Abbvie, Abbott, Biopas-UCB, Bristol, Janssen, Pfizer, Roche, Sanofi.

DCBG, FRF and GSV have no competing interests

\section{Funding}

This work has a grant for research from the Ministry of Sciences of Colombia - Colciencias grant number 695180763684

\section{Authors' contributions}


PSM, DBG and FRF conceived the research idea and study design, the acquisition of data, gathered the initial database for analysis, drafted the initial version of the manuscript, GSV provided a critical review of study results. All authors worked together on manuscript preparation and approved the final version for submission.

\section{Acknowledgements}

We thank Biomab IPS - Center of Rheumatoid Arthritis for the administrative data provided for this study

\section{References}

1. Schett G, Manger B, Simon D, Caporali R. COVID-19 revisiting inflammatory pathways of arthritis. Nature reviews Rheumatology. 2020:1-6.

2. Allen A, Carville $S$, McKenna F. Diagnosis and management of rheumatoid arthritis in adults: summary of updated NICE guidance. BMJ. 2018;362.

3. Gullick NJ, Scott DL. Co-morbidities in established rheumatoid arthritis. Best practice \& research Clinical rheumatology. 2011;25(4):469-83.

4. Sepriano A, Kerschbaumer A, Smolen JS, van der Heijde D, Dougados M, van Vollenhoven R, et al. Safety of synthetic and biological DMARDs: a systematic literature review informing the 2019 update of the EULAR recommendations for the management of rheumatoid arthritis. Annals of the Rheumatic Diseases. 2020;79(6):760.

5. Hall J, Julia Kaal K, Lee J, Duncan R, Tsao N, Harrison M. Patient Satisfaction and Costs of Multidisciplinary Models of Care in Rheumatology: a Review of the Recent Literature. Current Rheumatology Reports. 2018;20(4):19.

6. Riemsma RP, Taal E, Kirwan JR, Rasker JJ. Systematic review of rheumatoid arthritis patient education. Arthritis and rheumatism. 2004;51(6):1045-59.

7. Ziadé N, Hmamouchi I, el Kibbi L, Abdulateef N, Halabi H, Abutiban F, et al. The impact of COVID-19 pandemic on rheumatology practice: a cross-sectional multinational study. Clinical Rheumatology. 2020;39(11):3205-13.

8. Zhang Y, Wang J, Zhao L, Xiao J, Shi Z. Online management of rheumatoid arthritis during COVID-19 pandemic. Annals of the Rheumatic Diseases. 2020:annrheumdis-2020-217548.

9. Santos-Moreno P, Chavez-Chavez J, Hernández-Zambrano SM, Rivera-Triana DP, CastiblancoMontañez RA, Aza A, et al. Experience of telemedicine use in a big cohort of patients with rheumatoid arthritis during COVID-19 pandemic. Annals of the Rheumatic Diseases. 2020:annrheumdis-2020218165.

10. Rodriguez F, Villarreal L, Santos-Moreno P, Cabrera M, Buitrago-Garcia D, Caicedo C. THU0585 The patient's university - an innovative concept in the education of patients with rheumatoid arthritis. Annals of the Rheumatic Diseases. 2017;76(Suppl 2):427-. 
11. Mestre A, Fabrellas N, Perelló M, Pérez E, Martín E. De paciente pasivo a paciente activo. Programa Paciente Experto del Institut Català de la Salut. Revista de Innovación Sanitaria y Atención Integrada. 2008.

12. Fragoulis GE, Evangelatos G, Arida A, Bournia V-K, Fragiadaki K, Karamanakos A, et al. Treatment adherence of patients with systemic rheumatic diseases in COVID-19 pandemic. Annals of the Rheumatic Diseases. 2020:annrheumdis-2020-217935.

13. Michaud K, Wipfler K, Shaw Y, Simon TA, Cornish A, England BR, et al. Experiences of Patients With Rheumatic Diseases in the United States During Early Days of the COVID-19 Pandemic. ACR Open Rheumatol. 2020;2(6):335-43.

14. Pineda-Sic RA, Galarza-Delgado DA, Serna-Peña G, Castillo-Torres SA, Flores-Alvarado DE, EsquivelValerio JA, et al. Treatment adherence behaviours in rheumatic diseases during COVID-19 pandemic: a Latin American experience. Annals of the Rheumatic Diseases. 2020:annrheumdis-2020-218198.

15. Orso D, Federici N, Copetti R, Vetrugno L, Bove T. Infodemic and the spread of fake news in the COVID-19-era. European journal of emergency medicine: official journal of the European Society for Emergency Medicine. 2020.

16. Szmuda T, Özdemir C, Ali S, Singh A, Syed MT, Słoniewski P. Readability of online patient education material for the novel coronavirus disease (COVID-19): a cross-sectional health literacy study. Public health. 2020;185:21-5.

\section{Figures}

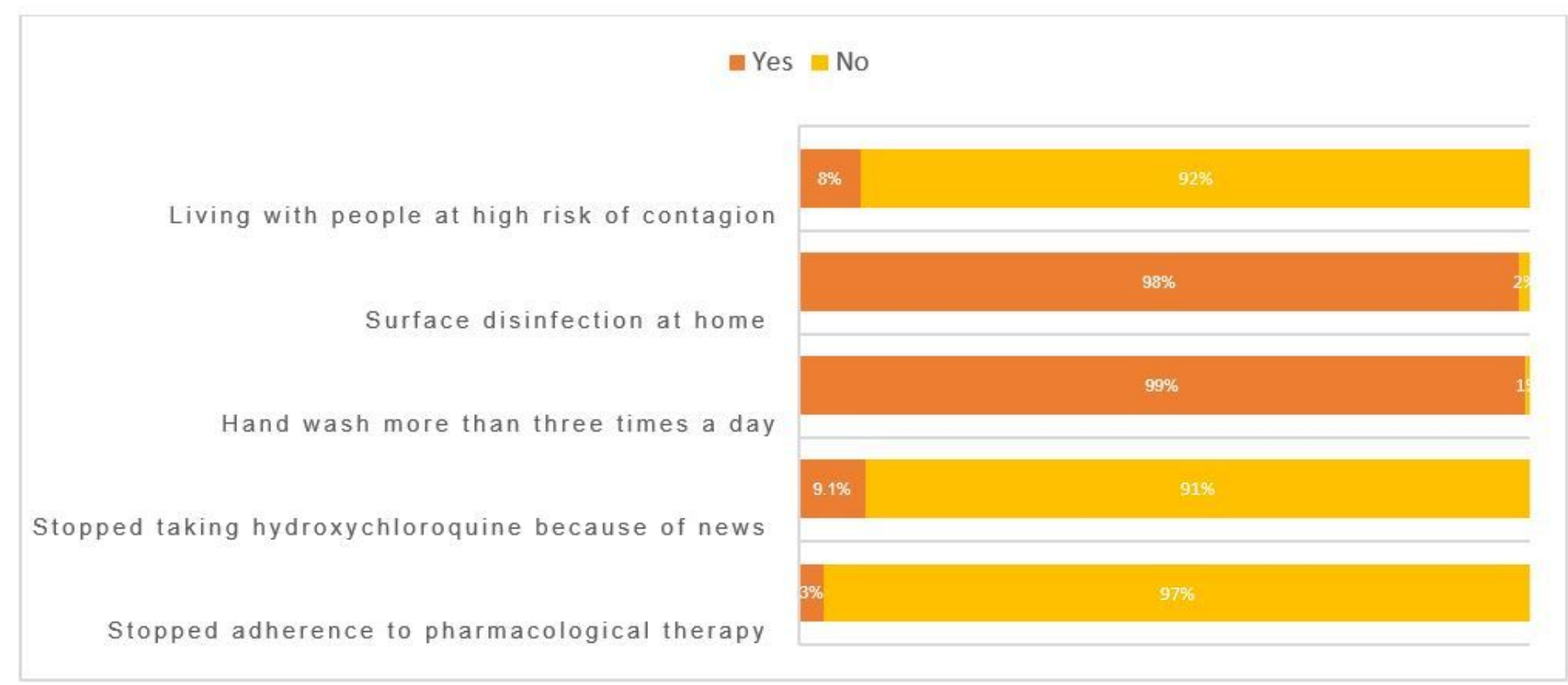

\section{Figure 1}

Behaviors, practices and its changes due to COVID-19 pandemic 